\title{
Otimização do desempenho de amplificadores de radiofrequência banda larga: uma abordagem experimental
}

\author{
Vanessa Borsato de Souza Lima ${ }^{\mathrm{a}, *}$, Pedro Paulo Balestrassi ${ }^{\mathrm{b}}$, \\ Anderson Paulo de Paiva ${ }^{c}$ \\ a,*vanessa@linear.com.br, UNIFEl, Brasil \\ bpedro@unifei.edu.br, UNIFEl, Brasil \\ cappaiva@unifei.edu.br, UNIFEl, Brasil
}

\begin{abstract}
Resumo
Neste trabalho buscou-se avaliar o comportamento de amplificadores de radiofrequência (RF) de potência em aplicações de telecomunicações. Uma estratégia experimental foi empregada resultando na otimização de um conjunto de fatores responsáveis pelo aumento da linearidade e eficiência geral do amplificador durante o processo produtivo, reduzindo com isto as intermodulações geradas e a interferência em serviços adjacentes. Estes resultados permitiram a manufatura de amplificadores banda larga de alta eficiência, garantindo assim maior produtividade e confiabilidade.
\end{abstract}

Palavras-chave

Amplificador de radiofrequência (RF). Intermodulação. Confiabilidade. DOE.

\section{Introdução}

A linearidade em amplificadores de radiofrequência (RF) de potência tem sido um dos requisitos mais importantes nos últimos anos para as diversas aplicações existentes em telecomunicações, dada a escassez de espectro para atender estas demandas em acentuado crescimento. Outro requisito de extrema importância é a eficiência elétrica de tais elementos, uma vez que o consumo de energia é um ponto bastante relevante para o cliente no momento de decisão da compra. Estes dois requisitos básicos para qualquer amplificador - linearidade e eficiência - são afetados e controlados por diversos fatores, os quais agem direta ou indiretamente no resultado final obtido. A definição de tais requisitos afeta questões relacionadas ao correto atendimento às especificações e critérios de qualidade, aos defeitos que levarão ao mau funcionamento dos amplificadores, e as falhas intermitentes ou até falhas generalizadas, que culminarão, muitas vezes, na queima de componentes.

Os processos de manufatura de amplificadores de RF são eminentemente multivariados, por se estabelecerem relacionamentos funcionais para as múltiplas características de saída a partir de um conjunto de fatores de entrada. Na indústria este comportamento pode levar a perdas significativas de qualidade e recursos, devido aos processos complexos incontroláveis e ao efeito desses fatores e ou de suas interações.

Com o elevado número de fatores e interações presentes no processo produtivo, frequentemente observa-se dispersões que levam a perdas de qualidade, rejeição de peças, ou até, em casos não detectados internamente ao sistema produtivo, a falhas em serviço. Um dos problemas decorrentes desta eventual falta de controle é a ocorrência de grandes variações no desempenho dos amplificadores, levando a dificuldades para se utilizar o mesmo amplificador ao longo de uma ampla faixa de frequência (amplificadores banda larga) e aumento na complexidade da especificação dos demais circuitos adjacentes ao amplificador, tais como filtros de canal e fontes de alimentação.

Este trabalho tem como objeto de estudo os amplificadores de potência utilizados para televisão 
digital na faixa de UHF. Utilizando uma abordagem experimental, diversos fatores são considerados no processo de amplificação, com o objetivo de reduzir a intensidade das intermodulações e aumentar a sua eficiência. Isto garante a padronização dos tempos de produção, bem como o aumento da confiabilidade dos produtos entregues aos clientes pela diminuição da variabilidade dos parâmetros de desempenho.

Esse trabalho está dividido da seguinte forma: uma descrição sobre o tema é descrita na seção 2, uma abordagem experimental para o problema é desenvolvida na seção 3 e as conclusões são apresentadas na seção 4.

\section{Processo de manufatura e avaliação de amplificadores de RF}

De acordo com a associação das indústrias de telecomunicações dos EUA (TIA Telecommunications Industry Association), a receita no mercado americano de wireless em 2005 foi de \$174,7 bilhões de dólares. Quase dois terços da população americana já haviam adquirido um serviço wireless e $88 \%$ pretendia adquirir um novo serviço até o ano de 2009 (JEONG, 2006). Embora os serviços de voz via celular já estivessem bem disseminados, a demanda por mais serviços e maior capacidade de tráfego de dados fez com que este mercado continuasse a se desenvolver, culminando nas novas tecnologias de transmissão como $3 G$ (terceira geração da telefonia móvel), $4 G$ (quarta geração da telefonia móvel) e Wimax (worldwide interoperability for microwave access). Além disso, outras tecnologias apareceram como LTE (long term evolution), televisão e rádios digitais. Em outras palavras, os serviços banda larga para voz, dados e vídeo se tornaram disponíveis em qualquer lugar, a qualquer momento e a um preço acessível.

Uma vez que o espectro de RF está bastante saturado e com poucas frequências restantes, estas novas tecnologias estão utilizando modulações altamente eficientes em termos de ocupação de banda e capacidade de transporte de dados. Estas modulações, em sua maioria do tipo QAM (quadrature amplitude modulation) ou OFDM (orthogonal frequency-division multiplexing), trazem uma grande economia de espectro, porém, dificultam a construção dos sistemas de transmissão por exigirem projetos mais eficientes, principalmente dos amplificadores de potência.

0 amplificador de potência é um elemento ativo, de natureza predominantemente não-linear, cuja principal função é entregar em sua saída um sinal com amplitude maior que ao de entrada, conforme mostra a Figura 1. A diferença entre a amplitude de saída e a amplitude de entrada é chamada de ganho do amplificador. Para se obter grandes áreas de cobertura para sistemas de telecomunicação, como cobertura de telefonia celular ou Wimax, faz-se necessário o uso de estações transmissoras

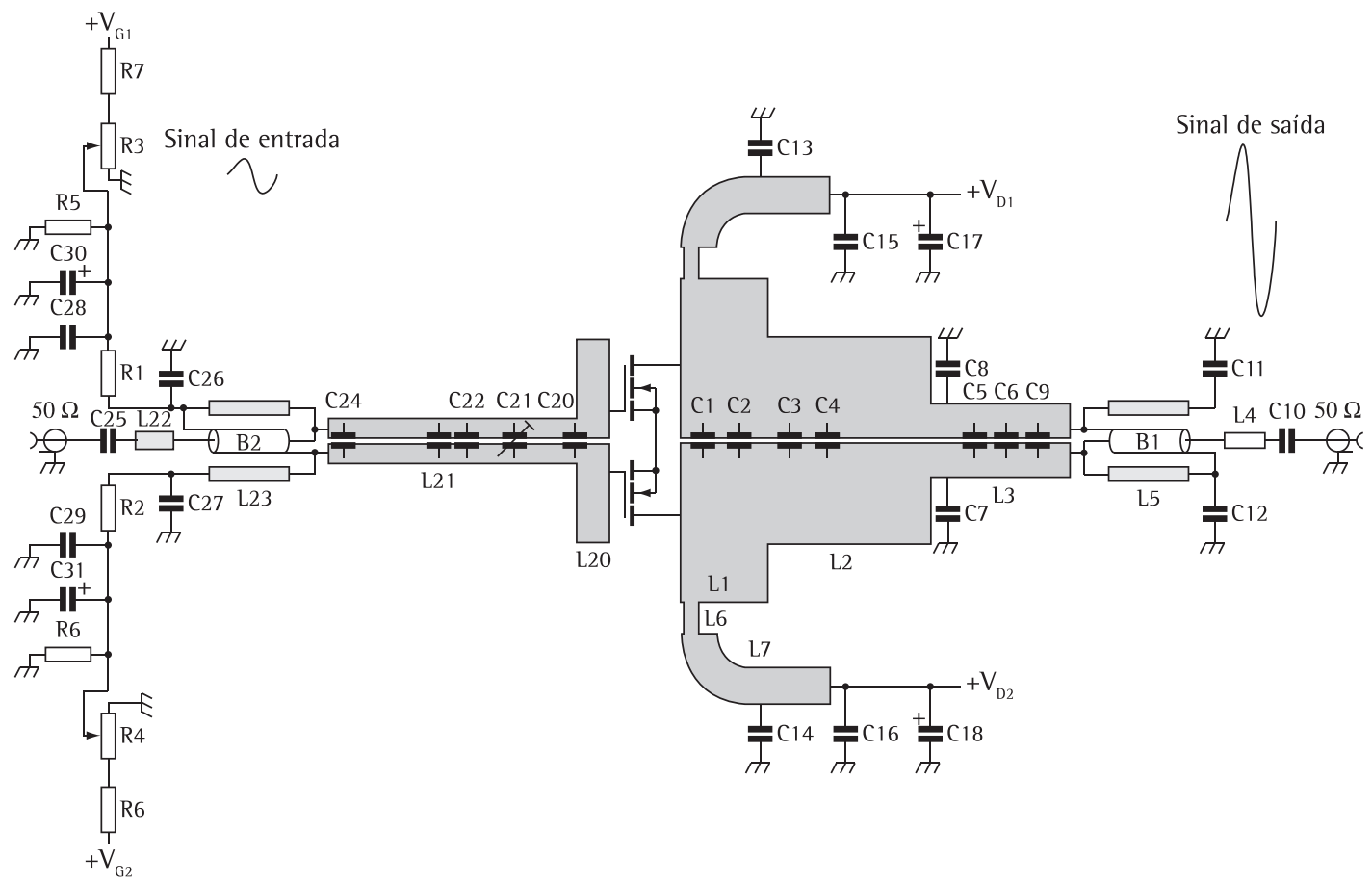

Figura 1. Um esquema eletrônico de um amplificador de potência. Fonte: Linear Equipamentos Eletrônicos SA. 
com elevadas potências de saída e, portanto, amplificadores com alto ganho. E para se obter estas elevadas potências, faz-se uso de um grande número de amplificadores de potência.

Este cenário representa uma grande oportunidade de crescimento para as empresas de telecomunicações, pois a demanda por amplificadores de potência vem aumentando expressivamente. Entretanto, o modelo tradicional de projeto e produção destes elementos leva a produtividade e confiabilidade baixas, dado o aspecto ainda bastante artesanal de manufatura. 0 uso de diversos componentes eletrônicos não disponíveis para montagem em máquinas, o posicionamento manual de transistores, a longa sequência de testes elétricos e a combinação de um grande número de amplificadores são alguns dos fatores que levam a uma grande dispersão nos resultados obtidos ao final de uma linha de produção.

\subsection{Respostas do processo}

À medida que as comunicações digitais têm sua utilização cada vez mais difundida, a linearidade dos amplificadores de RF se torna uma questão relevante. 0 grau de linearidade de um amplificador pode ser expresso através de sua intermodulação de saída. Quanto mais linear for um amplificador, menores serão as intermodulações em sua saída.

Entretanto, para que um amplificador seja comercializado, não basta que o mesmo seja apenas linear, devendo possuir também uma boa eficiência. Estes dois fatores, intermodulação de saída e eficiência, são as respostas deste processo de otimização e estão detalhados a seguir.

\subsubsection{Intermodulação de saída}

É desejável que o amplificador tenha o maior ganho possível. Porém, não é possível amplificar o sinal sem gerar distorções. 0 que se pode fazer é projetar o amplificador para que ele gere 0 menor número de distorções possíveis. Dentre as distorções geradas pelo amplificador, a que mais impacta o atendimento às máscaras de emissão é a intermodulação.

A intermodulação ocorre quando um sinal composto por mais de uma frequência é submetido a meios não lineares, como em um amplificador. Várias outras frequências são geradas como resultado das combinações lineares das frequências originais. Como outras frequências são geradas, o sinal amplificado passa a ocupar uma banda, ou largura de faixa, maior do que o sinal original. A Figura 2 traz um exemplo de intermodulação gerada ao se passar duas portadoras, ou dois sinais com frequências diferentes, por um mesmo amplificador.
As máscaras de emissão são elaboradas pelos órgãos reguladores responsáveis para delimitar os níveis adequados de intermodulação e emissões espúrias que um sistema de telecomunicações pode gerar. A Figura 3 exemplifica qual o nível de intermodulação exigido pelo FCC (Federal Communications Commission) e, portanto, o nível de intermodulação que os amplificadores devem atender para a aplicação em televisão digital.

Este parâmetro irá refletir o quanto um sinal, após a amplificação, ficará confinado dentro da largura de banda a ele destinado, não interferindo em serviços ou canais adjacentes. Quanto menor a intermodulação final, menor a interferência em outros serviços e melhor a qualidade do sinal para o usuário final. Quanto mais linear for o amplificador, menor será a intermodulação gerada em sua saída.

\subsubsection{Eficiência}

A potência fornecida pela fonte de alimentação $\left(\mathrm{P}_{\text {FONTE }}\right)$ é enviada à carga $\left(\mathrm{P}_{\text {CARGA }}\right)$ através do circuito amplificador que, devido às suas não linearidades, dissipará parte desta potência em forma de calor, como mostra a Figura 4. Sendo assim, quanto maior for a eficiência de um amplificador, maior será o aproveitamento da potência fornecida pela fonte e menor será a potência dissipada ou perdida.

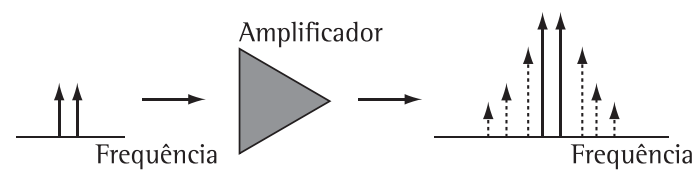

Figura 2. Intermodulação de duas portadoras após amplificação.

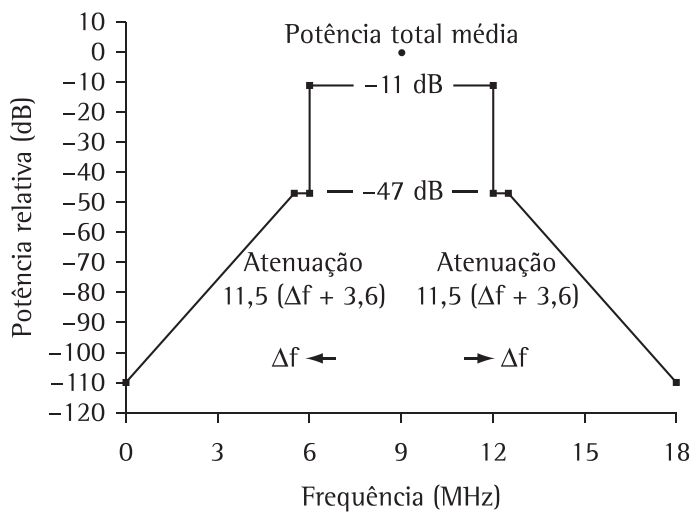

Figura 3. Máscara para intermodulação exigida pelo FCC para televisão digital. Fonte: Documento A/64B ATSC, (ADVANCED..., 2008, p. 7).

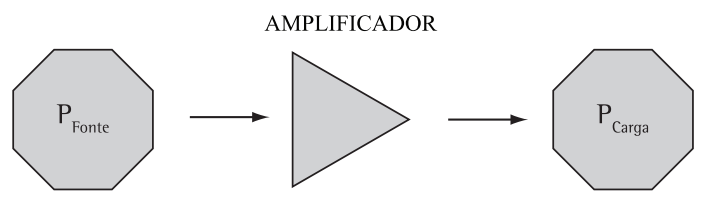

Figura 4. Conceito de eficiência. 
Este parâmetro mostra a capacidade que um determinado sistema tem de transformar a potência consumida em potência útil, e é representado pela relação abaixo:

$\eta_{\%}=\frac{P_{\text {CARGA }}}{P_{\text {FONTE }}} \times 100$

A eficiência irá refletir no consumo de energia do amplificador e, por consequência, no consumo total do equipamento de telecomunicações do qual ele fizer parte. É importante que se obtenha a maior potência final amplificada consumida com a menor energia elétrica possível, ou seja, a maior taxa de conversão de kVA consumido da rede elétrica em potência eficaz entregue para a carga.

\subsection{Fatores}

Diversossão os fatores que devem ser considerados no processo produtivo de amplificadores de RF de potência, passíveis de interferirem nas respostas desejadas de intermodulação de saída e eficiência. Usando o conhecimento de especialistas e de literatura especializada, os seguintes fatores (e suas possíveis interações) podem ser considerados fundamentais.

\subsubsection{Corrente de polarização}

Para qualquer transistor operar adequadamente, é necessário realizar a sua polarização, que consiste na definição de uma tensão contínua a partir da qual o sinal a ser amplificado irá excursionar, conforme mostra a Figura 5.

A corrente de polarização irá definir o ponto de operação do transistor, bem como sua classe. 0 fabricante geralmente especifica um valor ótimo para esta corrente, mas a sua alteração traz reflexos no desempenho final do amplificador e pode ser alterada, dentro de limites seguros. É importante que o amplificador tenha um circuito de correção da transcondutância $\left(\mathrm{G}_{\mathrm{m}}\right)$, pois a mesma varia com o envelhecimento do transistor e com a variação da temperatura de trabalho, afetando diretamente a corrente de polarização.

\subsubsection{Classes de operação}

0 elemento ativo do amplificador, o transistor, tem uma curva de operação, isto é, uma curva que indica a relação funcional entre a entrada e a saída. 0 nível de polarização e os níveis máximos e mínimos do sinal de entrada definem a faixa da curva em que o amplificador irá operar. Diferentes faixas de operação implicam diferentes resultados em termos de eficiência, distorção, intermodulação, entre outros. Às faixas comuns de operação de amplificadores dá-se o nome de classe de operação.

A classe de operação do amplificador tem influência direta na quantidade de intermodulação gerada. Amplificadores operando em Classe $A$ apresentam a menor intermodulação de saída, porém são extremamente ineficientes. São, portanto, comumente utilizados para amplificação de pequenos sinais.

Já para amplificadores de potência, faz-se necessário o uso de amplificadores mais eficientes, como os em Classe $A B$. A consequência disto é uma maior quantidade de intermodulação na saída. lsto acontece pelo fato de nesta classe o transistor operar em uma região mais não linear. A Figura 6 exemplifica a diferença entre Classe $A$ e Classe $A B$.

Pode-se perceber que mesmo operando em Classe $A B$, é importante escolher cuidadosamente a corrente de polarização, pois ela irá definir a faixa de excursão do sinal de saída. Se houver ceifamento (clipping) do sinal de saída, haverá distorção e, portanto, maior intermodulação na saída.

Existem outras classes de operação, porém as mais utilizadas em amplificadores para transmissores de televisão são as duas apresentadas acima.

\subsubsection{Potência e intermodulação de entrada}

A potência de entrada do amplificador é um dado importante, pois o sistema que irá anteceder o amplificador de potência já apresenta uma quantidade de intermodulação inerente, por não

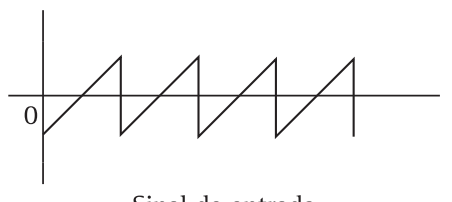

Sinal de entrada

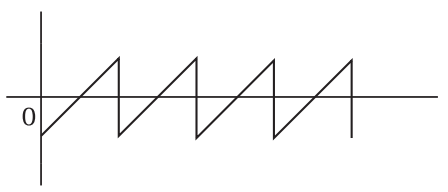

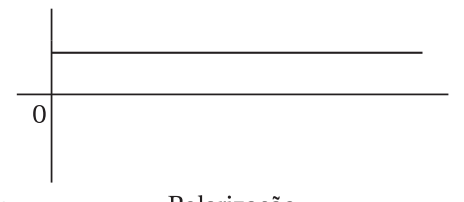

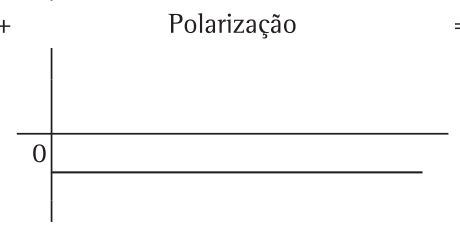

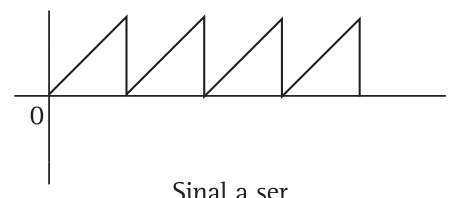

Sinal a ser amplificado

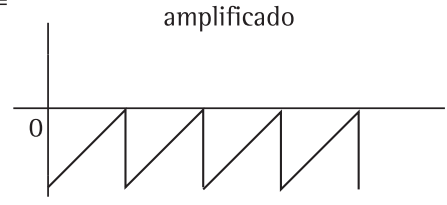

Figura 5. Efeito da polarização no sinal de entrada a ser amplificado. 
se tratar de um sistema ideal. Assim, é importante conhecer este fator, pois quanto mais linear for a fonte de sinal, mais caro fica o sistema. É importante conhecer o maior valor de intermodulação e de potência de entrada que o sistema pode suportar para dimensionar o sistema para o menor custo.

\subsubsection{Faixa de frequência ou canal de operação}

A quantidade de intermodulação gerada também varia de acordo com a frequência fundamental do sinal, ou seja, com o canal de operação do amplificador. Para uma mesma aplicação em telecomunicações, é desejável que o mesmo amplificador de potência seja usado para cobrir uma grande faixa de frequências. Isto facilita o processo produtivo e o controle de qualidade, além de reduzir o número de itens de estoque. Dependendo da aplicação em telecomunicações, os órgãos reguladores destinam frequências de operação variadas. Este parâmetro deve ser levado em consideração, pois o comportamento do transistor muda ao longo do tempo e da frequência.

Tornar o amplificador banda larga, ou seja, capaz de cobrir uma ampla faixa de frequências de operação, é uma característica altamente desejável pela indústria, porém bastante complexa de ser atingida. É comum ver um mesmo amplificador customizado para diversas bandas pelo fato de não ter sido possível torná-lo banda larga. Porém, isto provoca um aumento de estoque, dilata o tempo de produção e torna o controle de qualidade mais complexo.

\subsubsection{Temperatura de operação}

Todo semicondutor trabalha com átomos dopados, ou seja, com elétrons inseridos ou retirados da última camada de valência. Desta forma, seu comportamento é fortemente afetado pela temperatura do ambiente no qual ele opera. Assim, deve-se analisar o comportamento do

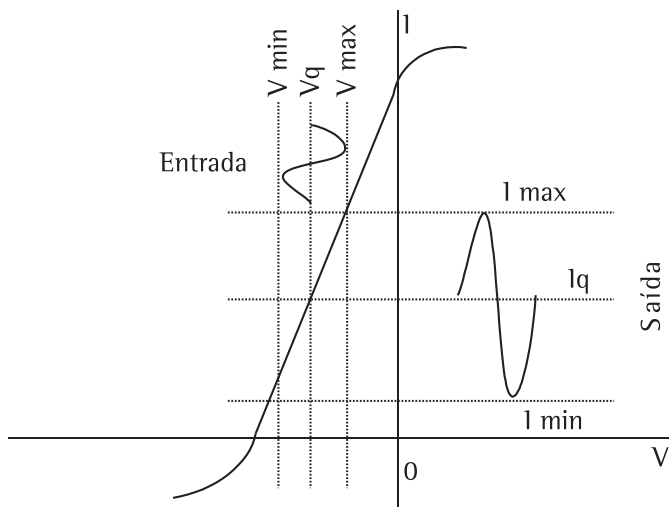

Classe A amplificador para diferentes condições de operação do semicondutor. A temperatura ambiente afetará diretamente a temperatura da junção, ou seja, a temperatura interna de trabalho do transistor. Esta, em sua quase totalidade, não deve ultrapassar $200^{\circ} \mathrm{C}$, sob pena de dano permanente no componente. A temperatura também afeta a corrente de polarização do transistor, sendo necessário o uso de circuitos para compensar a variação do comportamento do dispositivo com a variação da temperatura. Quanto mais baixa for a temperatura da junção do transistor, maior será a sua vida útil.

\subsubsection{Montadora manual}

Dispositivos de RF para altas potências como transistores, bobinas e capacitores não são comercializados em encapsulamentos compatíveis com montagem a máquina. Assim, estes componentes são colocados na placa de circuito impresso de forma manual. Desta forma, há variações entre as diversas montadoras manuais na finalização da manufatura, que devem ser observadas afim de manter um mesmo padrão de qualidade.

\subsubsection{Ruído na alimentação DC}

Os amplificadores trabalham com tensão de alimentação contínua $(D C)$ já regulada e filtrada. Se a quantidade de filtragem aplicada na fonte de alimentação não for bem dimensionada ou for de má qualidade, isto refletirá na qualidade do sinal final amplificado, pois o ruído estará sobreposto na tensão e corrente de polarização e poderá deslocar o ponto de operação do transistor.

Os ruídos podem também ser provenientes de raios ou surtos na rede elétrica, sendo, portanto, importante utilizar bons circuitos de desacoplamento, blindagem adequada e instalação apropriada para os amplificadores.

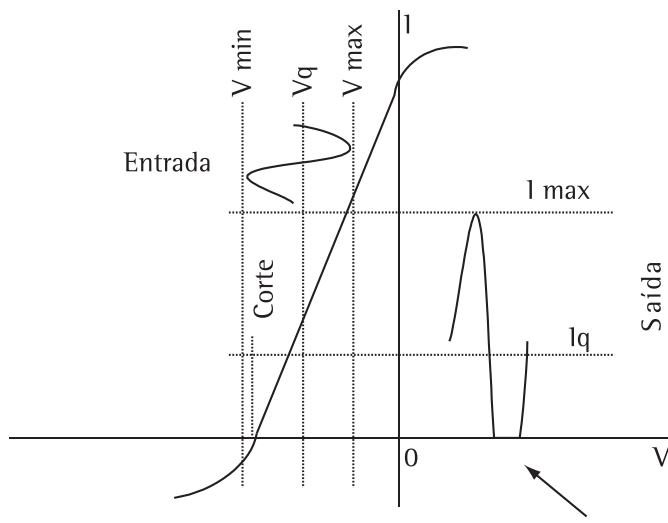

Classe $A B$

Figura 6. Classe $A \times$ Classe $A B$. 


\subsubsection{Tipo do transistor}

Para cada aplicação em telecomunicações existe um transistor mais adequado em termos da frequência de operação e a máxima potência de saída possivel de se obter. Existem diversos fabricantes de transistores no mercado e é de extrema importância, ao se iniciar um novo projeto, escolher de forma precisa o componente que traga a melhor relação custo/benefício.

É importante ressaltar que todas as características citadas estão diretamente relacionadas ao transistor utilizado. Se houver mudança no transistor empregado, todos estes fatores deverão ser reavaliados. Na indústria é comum realizar a troca de transistores uma vez por ano. A cada troca de transistores deve-se atentar para que não haja degradação do desempenho pré-estabelecido.

\subsubsection{Linearização}

Um recurso amplamente utilizado para se obter maior linearidade, ou menor intermodulação, dos amplificadores é o chamado back-off de potência. 0 back-off restringe a excursão do sinal de saída através da redução da potência amplificada final. Este recurso reduz a intermodulação, porém degrada enormemente a eficiência do amplificador, portanto, não pode ser considerado como solução comercial.

A técnica amplamente utilizada para conciliar redução de intermodulação com o aumento de eficiência elétrica é a linearização. Esta técnica consiste em manipular o sinal a ser entregue ao amplificador de potência de tal forma que ele contenha uma distorção contrária a distorção a ser inserida pelo amplificador. Assim, quando o sinal for amplificado, a intermodulação resultante será expressivamente reduzida, como mostra a Figura 7.

Atualmente, é praticamente impossivel estar em conformidade com as legislações vigentes para emissões fora da banda sem o uso de alguma técnica de linearização. Há diversas técnicas amplamente difundidas no mercado como digital pre-distorion, feed forward, RF pre-distortion etc, sendo cada uma delas mais aplicável em determinado circuito. Devese, portanto, escolher o método mais aconselhável durante a fase de projeto do amplificador.

Desta forma, como há muitos fatores envolvidos, faz-se necessário utilizar uma abordagem otimizada para projetar e produzir amplificadores de RF, visando acelerar o desenvolvimento e avaliação destes, levando em consideração os fatores citados. Estes fatores são de extrema importância durante a fase de projeto do amplificador, mas também devem ser monitorados durante o processo produtivo, pois a observação constante poderá indicar dispersões dignas de atenção. A Figura 8 mostra como os fatores apresentados se relacionam fisicamente com o amplificador de RF.

\section{Experimentos e análise}

Dada a demanda apresentada pelo setor de telecomunicações por amplificadores mais eficientes, mais lineares e capazes de atender o maior número de aplicações possíveis, ou seja, serem banda larga para atenderem uma ampla faixa de frequências de operação, vê-se a necessidade de analisar a questão e propor uma metodologia para melhoria do processo produtivo. Em suma, o presente trabalho de pesquisa pode ser assim sintetizado:

A existência de altos níveis de intermodulação em amplificadores de RF de potência pode comprometer a qualidade do produto final e/ou gerar falhas catastróficas com severas consequências para os usuários finais. As principais questões a serem investigadas nesse estudo são: i) quais fatores envolvidos no processo de amplificação são responsáveis pelo aumento de intermodulações? ii) como esses fatores se relacionam com a eficiência? iii) como estes fatores podem ser controlados visando aumentar a qualidade do produto e a produtividade? iv) como um mesmo amplificador pode ser utilizado para atender o maior número possivel de cliente, ou seja, ser banda larga?

A Figura 9 mostra um conjunto de dados históricos obtidos de um amplificador. Pode-se observar nesta figura que há uma grande dispersão dos valores de intermodulação e eficiência dentro da faixa de frequências de UHF, que são representadas numericamente pelos canais de número 14 a 69 . lsto faz com que este amplificador não possa ser considerado um amplificador banda larga, havendo a necessidade de customizá-lo para cada frequência de operação, ou seja, não é possível utilizar o

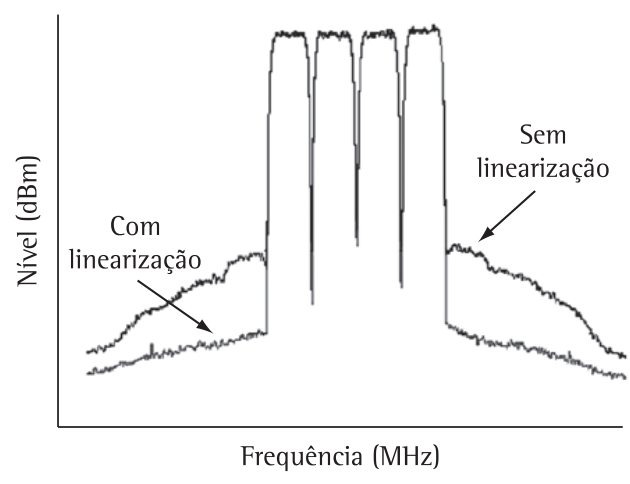

Figura 7. Resultados obtidos após o uso de técnica de linearização. 
mesmo amplificador para todas as frequências de UHF. 0 ideal seria obter um mesmo valor de intermodulação e eficiência para todos os canais com mínima variabilidade.

Devido ao elevado número de fatores envolvidos no processo e a complexidade das potenciais interações entre estes para controle e robustez do processo de projeto e produção de amplificadores de RF de potência, o uso de Delineamento de Experimentos (Design of Experiments - DOE) é a metodologia natural a ser adotada. Coleman e Montgomery (1993) sugerem que a solução de problemas de processos industriais pode ser alcançada com mais facilidade e robustez quando o experimento é planejado e as respostas analisadas com métodos e técnicas estatísticas.

\subsection{Experimentos exploratórios}

Os diversos fatores considerados na seção anterior foram classificados por um grupo de especialistas do ramo de telecomunicações em seções de brainstorm, conforme mostra a Tabela 1. Este grupo também definiu e atribuiu um índice

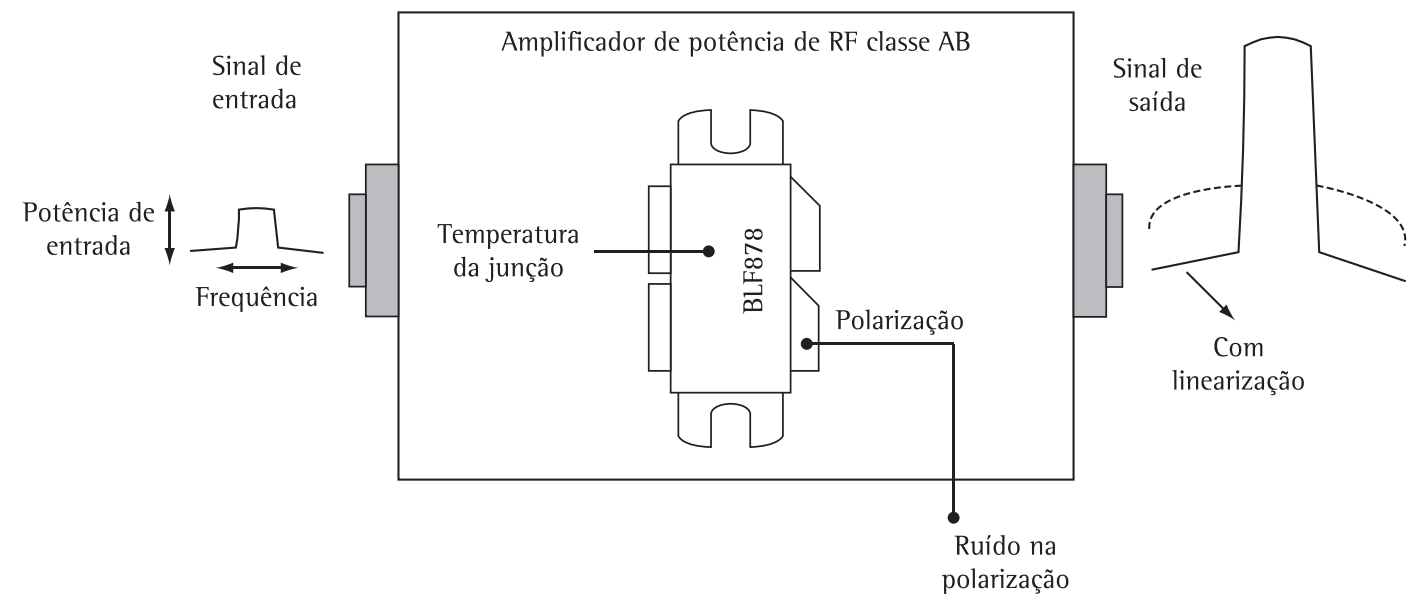

Figura 8. Fatores envolvidos e sua relação com o modelo físico do amplificador.
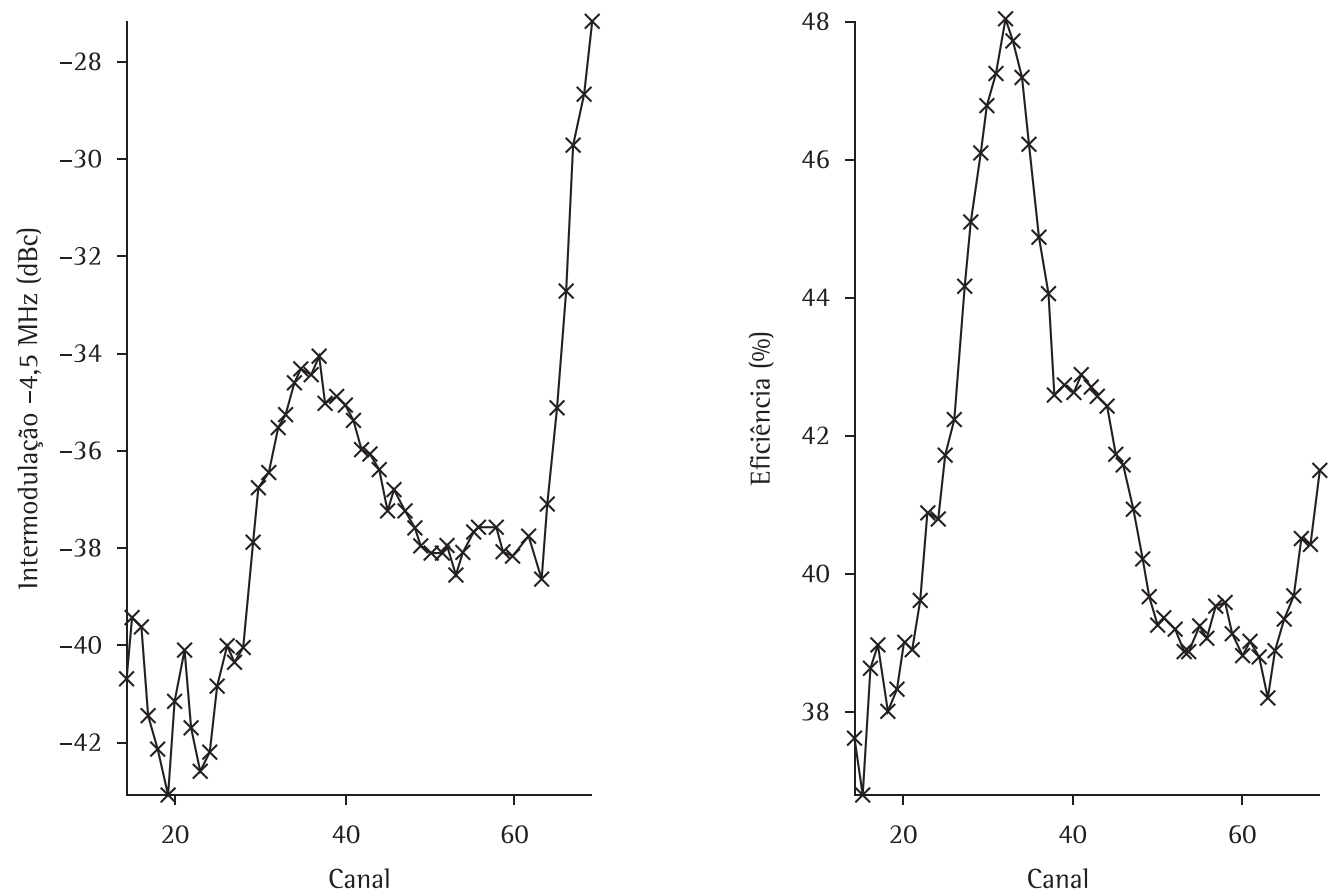

Figura 9. Dados históricos para intermodulação e eficiência. 
denominado de sensibilidade associada ao controle dos fatores no processo (fatores de médio controle (1) e controláveis (2)).

A equipe decidiu pela investigação experimental de todos os fatores utilizando um planejamento de experimentos exploratórios onde as respostas na saída de cada amplificador são mostradas na Tabela 2. Estas respostas são afetadas diretamente, em maior ou menor grau, pelos fatores listados na Tabela 1.

Os projetos experimentais de Taguchi e de Plackett-Burman são naturais candidatos a projetos exploratórios. Optou-se pela abordagem tradicional de Plackett-Burman devido a característica de ortogonalidade, o que permite que os efeitos principais de cada fator sejam determinados individualmente, admitindo-se que os efeitos de interação sejam desprezíveis. Este modelo, além de ser adequado para situações exploratórias, também pode ser utilizado em pesquisas economicamente enxutas, pois permite com $n$ experimentos investigar $n-1$ fatores e utiliza-se de fatores "fantasmas", os quais servem para fazer a estimativa do erro experimental (BARROS NETO; SCARMÍNIO; BRUNS, 2003). Assim como os experimentos de Taguchi, os experimentos de Plackett-Burman podem ser considerados de resolução 111 , onde os efeitos principais dos fatores estão confundidos com os efeitos de interações de segunda ordem. Esse é um custo a se pagar para se analisar um grande número de fatores. Os resultados exploratórios, contudo, indicam uma nova fase experimental a ser projetada.

A matriz de Plackett-Burman gerada com os respectivos resultados de Intermodulação $\left(\mathrm{Y}_{1}\right)$ e Eficiência $\left(Y_{2}\right)$, considerando os nove fatores definidos na Tabela 1 e seus respectivos níveis, são mostrados na Tabela 3.

Tabela 1. Análise exploratória dos fatores potenciais influentes no processo.

\begin{tabular}{cc}
\hline Fator & Sensibilidade \\
\hline Tipo do transistor & 2 \\
Corrente de polarização & 2 \\
Potência de entrada & 2 \\
Canal de operação & 2 \\
Classe de operação & 1 \\
Uso de linearização & 2 \\
Temperatura de operação & 1 \\
Montadora manual & 1 \\
Ruído na alimentação DC & 1 \\
\hline Obs.: 1 = Médio controle, 2 = Controlável &
\end{tabular}

Tabela 2. Respostas esperadas.

\begin{tabular}{clc}
\hline $\mathrm{Y}$ & \multicolumn{1}{c}{ Nome } & Tipo de Resposta \\
\hline$Y_{1}$ & Intermodulação de Saída $(\mathrm{dBc})$ & Menor melhor \\
$\mathrm{Y}_{2}$ & Eficiência (\%) & Maior melhor \\
\hline
\end{tabular}

A Figura 10 mostra a sequência de realização das medições das duas respostas consideradas para os doze ensaios aleatorizados da matriz de PlackettBurman.

A Figura 11 mostra os resultados de análise dos efeitos principais dos fatores envolvidos no experimento exploratório. Para a resposta Y. (Intermodulação) os fatores Linearização, Temperatura, Potência, Corrente, Classe e Canal se mostraram significativos (Valor $\mathrm{P}<0.005)$. Para a resposta $Y_{2}$ (Eficiência) os fatores linearização, Potência, Corrente, Classe e Canal também se mostraram significativos. Os demais fatores foram considerados insignificantes.

A partir dos resultados obtidos no experimento exploratório, foi possivel desprezar os fatores que menos impactaram nas respostas desejadas em um estudo consecutivo. Os fatores excluídos foram mantidos sob controle, fixando-os em um nível de fácil controle e de baixo custo. Os principais fatores significativos foram fixados em seus níveis no sentido de otimizar as duas respostas desejadas. Alguns fatores, passiveis de terem seus efeitos confundidos com interações foram selecionados para uma segunda fase experimental. A Tabela 4 sintetiza os resultados obtidos pelo DOE exploratório de Plackett-Burman.

\subsection{Metodologia de superfície de resposta}

No contexto do planejamento de experimentos, é possível caracterizar a relação entre uma ou mais respostas a um conjunto de fatores de interesse. Para o nosso caso a seguinte relação é apropriada:

(Intermodulação, eficiência $)=f($ corrente, potência, canal $)$

0 conhecimento da forma funcional de $f$, frequentemente obtido com a modelagem de dados provenientes de experimentos planejados, permite tanto sumarizar os resultados do experimento quanto predizer a resposta para valores dos fatores. Assim, a função $f$ define a superfície de resposta. Podemos então definir a superfície de resposta como sendo a representação geométrica obtida quando uma resposta é traçada como uma função de um ou mais fatores quantitativos.

No planejamento de experimentos para estudar ou ajustar superfícies de resposta, a função de resposta é caracterizada em uma região de interesse do pesquisador, para que seja possível utilizá-la na prática. Após o ajuste do modelo aos dados, é possível estimar a sensibilidade da resposta aos fatores, além de determinar os níveis dos fatores nos quais as respostas são ótimas (por exemplo, máxima ou mínima). 


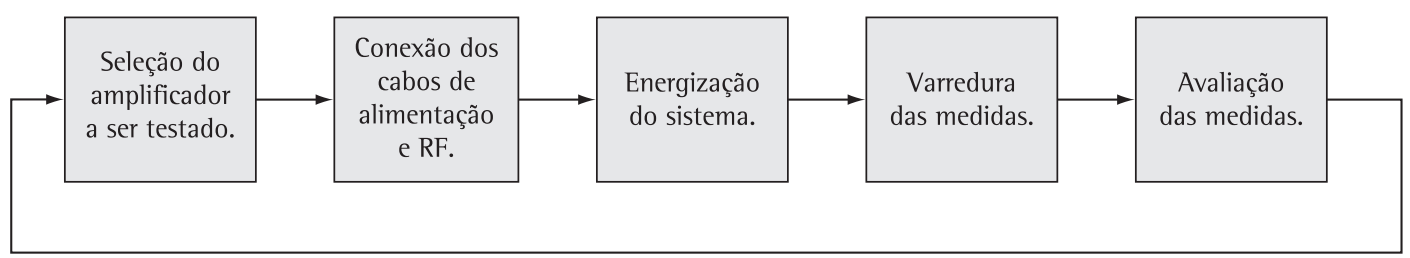

Figura 10. Processo de medidas.
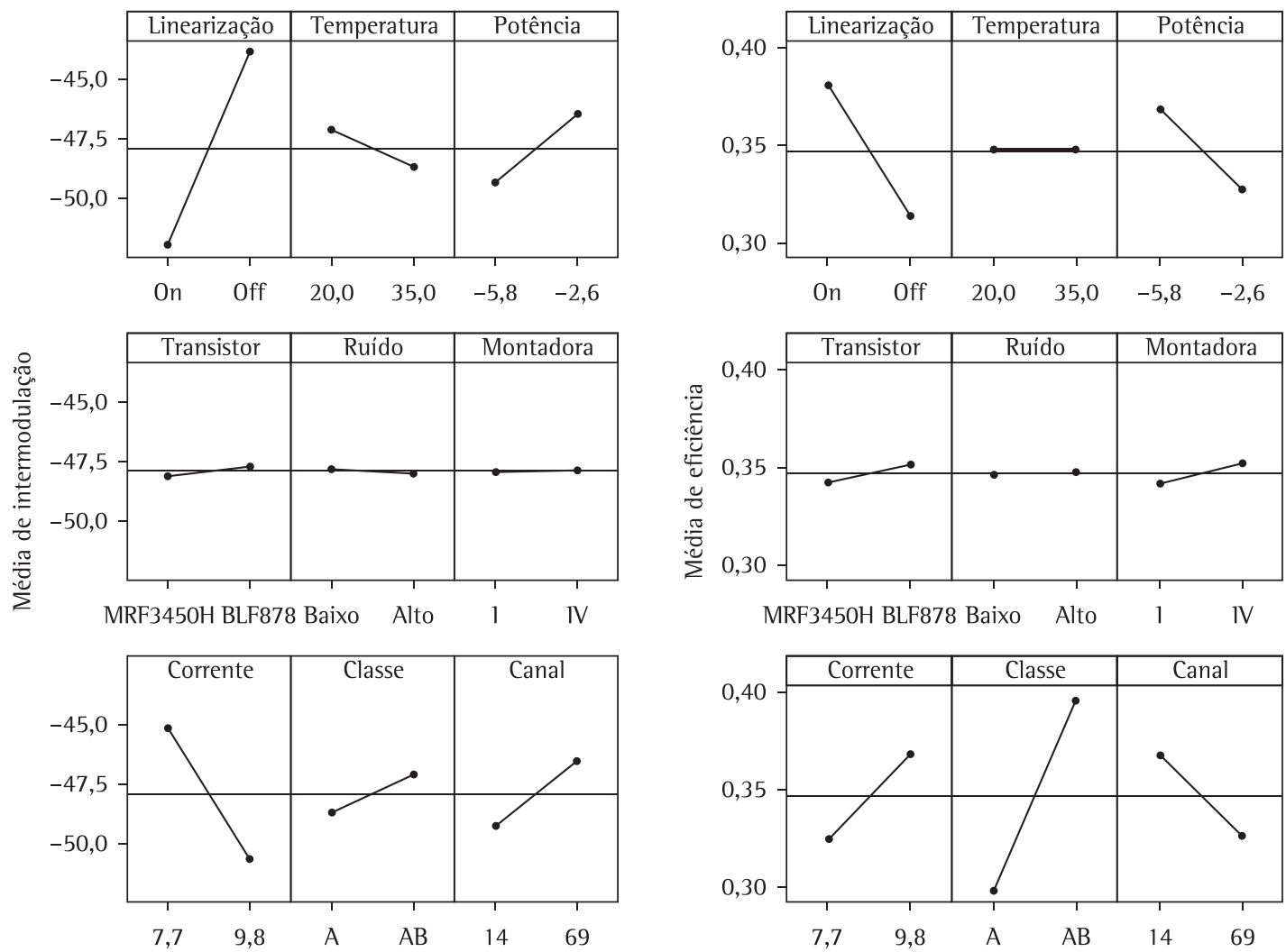

Figura 11. Análise dos efeitos principais.

Tabela 3. Matriz de Plackett-Burman.

\begin{tabular}{ccccllllllllc}
\hline Ensaio & Linear. & Temp. $\left({ }^{\circ} \mathrm{C}\right)$ & Pot. $(\mathrm{dBm})$ & Transistor & Ruido & Montad. & Corrent. (A) & Classe & Canal & $\mathrm{Y}_{1}$ & $\mathrm{Y}_{2}$ \\
\hline 1 & On & 20 & $-5,8$ & BLF878 & Alto & IV & 7,7 & AB & 69 & $-48,55$ & 0,41 \\
2 & On & 20 & $-5,8$ & MRF3450H & Baixo & I & 7,7 & A & 14 & $-52,23$ & 0,34 \\
3 & On & 35 & $-2,6$ & BLF878 & Baixo & IV & 9,8 & A & 69 & $-53,20$ & 0,32 \\
4 & Off & 20 & $-2,6$ & BLF878 & Baixo & IV & 7,7 & A & 14 & $-40,58$ & 0,25 \\
5 & Off & 35 & $-5,8$ & BLF878 & Alto & I & 9,8 & A & 14 & $-51,94$ & 0,32 \\
6 & Off & 35 & $-2,6$ & MRF3450H & Alto & IV & 7,7 & AB & 14 & $-41,34$ & 0,34 \\
7 & On & 20 & $-2,6$ & BLF878 & Alto & I & 9,8 & AB & 14 & $-51,83$ & 0,46 \\
8 & On & 35 & $-5,8$ & MRF3450H & Baixo & IV & 9,8 & AB & 14 & $-57,60$ & 0,49 \\
9 & Off & 20 & $-5,8$ & MRF3450H & Alto & IV & 9,8 & A & 69 & $-46,01$ & 0,29 \\
10 & Off & 35 & $-5,8$ & BLF878 & Baixo & 1 & 7,7 & AB & 69 & $-39,80$ & 0,34 \\
11 & Off & 20 & $-2,6$ & MRF3450H & Baixo & I & 9,8 & AB & 69 & $-43,29$ & 0,33 \\
12 & On & 35 & $-2,6$ & MRF3450H & Alto & I & 7,7 & A & 69 & $-48,29$ & 0,26 \\
\hline
\end{tabular}


Dentre as diversas metodologias existentes, temos a metodologia de experimentos centrais compostos (CCD - Central Composite Design), através da qual podemos criar experimentos centrais com ou sem blocos. Como exemplo, um $C C D$ com dois fatores é mostrado na Figura 12. Os pontos no diagrama representam os ensaios experimentais que são realizados.

A partir do experimento exploratório, o grupo decidiu por uma investigação dos fatores quantitativos possíveis de serem confundidos com interações envolvendo superfícies de resposta. Estes níveis foram escolhidos também com a premissa de cobrirem as especificações de um amplificador banda larga. A Tabela 5 apresenta os fatores de estudo e os níveis selecionados para a fase experimental da superfície de resposta.

A Tabela 6 mostra a matriz de experimento e repostas segundo a metodologia de experimentos centrais compostos. Podem ser observados níveis na tabela pontos fatoriais, pontos axiais e pontos centrais. 0 número de experimentos foi escolhido para favorecer superfícies de resposta considerando termos quadráticos e termos de interação.

As Tabelas 7 e 8 trazem as análises estatísticas deste experimento, apresentando os coeficientes de regressão linear estimados para intermodulação

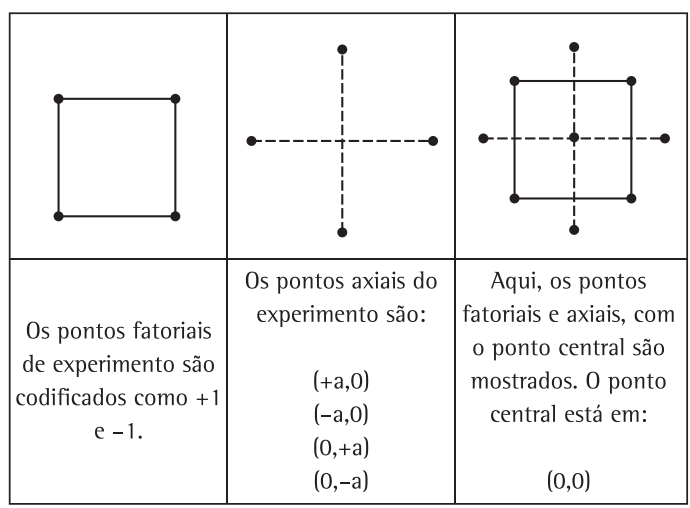

Figura 12. Experimento central composto com dois fatores. e eficiência, respectivamente. Primeiramente, os Valores- $P$ determinam quais dos efeitos do modelo são estatisticamente significativos. Pela análise de variância, têm-se evidências suficientes de que o modelo utilizado é adequado para explicar a relação desses fatores com a resposta. 0 valor de $\mathrm{R}-\mathrm{Sq}$, que representa a proporção da variação na resposta explicada pelo modelo, é de $97,6 \%$ para a Eficiência e de $86,5 \%$ para a Intermodulação, o que também mostra a adequação deste modelo. Os Valores- $P$ mostram que a Intermodulação é afetada pela Corrente e Canal. A Eficiência é afetada pela Corrente e Potência. As interações Corrente-Potência e Corrente-Canal mostram-se significantes para a Intermodulação. Termos quadráticos também estão presentes nos modelos. Valores em negrito de Valores- $P$ mostram os fatores significativos dos modelos para as duas respostas.

Procedendo à análise estatística dos dados, muitas estatísticas e gráficos podem ser utilizados. Quando a superfície de resposta é uma função de dois ou mais fatores, como nesse caso, os resultados podem ser descritos graficamente. Gráficos de contorno e superfície são úteis para estabelecer condições de operação para se obter valores desejáveis da resposta. Em um gráfico de superfície, os valores dos dois fatores são representados nos eixos $x$ e $y$, enquanto os valores da resposta são representados no eixo $z$. Esse gráfico fornece uma visão tridimensional que pode exibir um desenho mais claro da superfície de resposta.

Uma condição necessária para o uso de DOE consiste na análise estatística dos resíduos, através do gráfico de probabilidade normal dos resíduos, para verificar se estes não se desviam de forma substancial de uma distribuição normal. Se os

Tabela 5. Fatores e níveis do estudo experimental.

\begin{tabular}{ccc}
\hline Fator de Estudo & Nível - & Nível + \\
\hline Corrente de polarização (A) & 8,1 & 9,3 \\
Potência de entrada (dBm) & $-4,6$ & $-3,8$ \\
Canal de UHF (\#) & 28 & 49 \\
\hline
\end{tabular}

Tabela 4. Decisão sobre os fatores de estudo a partir do DOE de Plackett-Burman

\begin{tabular}{ccc}
\hline Fator & Justificativa & Decisão \\
\hline Tipo do transistor & Seleção do BLF878, pela maior eficiência & Fixar \\
Corrente de polarização & Analisar em um segundo DOE & Analisar \\
Potência de entrada & Analisar em um segundo DOE & Analisar \\
Canal de operação & Analisar em um segundo DOE & Analisar \\
Classe de operação & Seleção da Classe AB, pela maior eficiência & Fixar \\
Uso de linearização & Seleção por ON, pelo ganho nas duas respostas & Fixar \\
Temperatura de operação & Fixação na temperatura ambiente de $25{ }^{\circ} \mathrm{C}$ & Fixar \\
Montadora manual & Fixação na montadora 2 & Fixar \\
Ruído DC & Fixação em ruído baixo & Fixar \\
\hline
\end{tabular}


Tabela 6. Matriz de experimento e respostas.

\begin{tabular}{|c|c|c|c|c|c|}
\hline Ensaio & Corrente & Potência & Frequência & $Y_{1}$ & $Y_{2}$ \\
\hline 1 & 9,7 & $-5,8$ & 14 & $-48,8$ & 0,375 \\
\hline 2 & 9,2 & $-4,8$ & 21 & -49 & 0,391 \\
\hline 3 & 8,0 & $-4,8$ & 28 & $-49,6$ & 0,440 \\
\hline 4 & 7,8 & $-5,4$ & 35 & $-47,5$ & 0,464 \\
\hline 5 & 8,4 & $-4,2$ & 42 & $-48,3$ & 0,433 \\
\hline 6 & 8,9 & $-4,7$ & 49 & $-49,2$ & 0,400 \\
\hline 7 & 9,3 & $-3,6$ & 56 & $-49,3$ & 0,397 \\
\hline 8 & 8,4 & $-3,8$ & 69 & $-44,2$ & 0,384 \\
\hline 9 & 9,7 & $-5,3$ & 14 & $-49,8$ & 0,376 \\
\hline 10 & 8,9 & $-4,4$ & 21 & -49 & 0,389 \\
\hline 11 & 8,1 & $-4,1$ & 28 & -50 & 0,450 \\
\hline 12 & 7,9 & $-4,8$ & 35 & $-47,3$ & 0,461 \\
\hline 13 & 8,5 & $-3,9$ & 42 & -49 & 0,426 \\
\hline 14 & 9,0 & $-4,7$ & 49 & -50 & 0,396 \\
\hline 15 & 9,2 & $-3,9$ & 56 & -50 & 0,390 \\
\hline 16 & 8,8 & $-2,9$ & 69 & $-41,7$ & 0,414 \\
\hline 17 & 9,5 & $-5,2$ & 14 & $-49,6$ & 0,371 \\
\hline 18 & 9,1 & $-4,2$ & 21 & $-49,1$ & 0,406 \\
\hline 19 & 7,9 & -4 & 28 & -50 & 0,459 \\
\hline 20 & 7,7 & $-4,6$ & 35 & $-46,5$ & 0,474 \\
\hline 21 & 8,4 & $-3,7$ & 42 & $-47,8$ & 0,436 \\
\hline 22 & 9,3 & $-4,2$ & 49 & $-49,1$ & 0,399 \\
\hline 23 & 9,5 & $-3,2$ & 56 & -49 & 0,378 \\
\hline 24 & 8,8 & $-3,1$ & 69 & $-42,9$ & 0,418 \\
\hline 25 & 9,5 & -5 & 14 & $-49,1$ & 0,371 \\
\hline 26 & 9,0 & $-4,2$ & 21 & $-49,4$ & 0,407 \\
\hline 27 & 7,9 & $-4,2$ & 28 & $-49,8$ & 0,460 \\
\hline 28 & 7,9 & $-4,7$ & 35 & $-46,8$ & 0,464 \\
\hline 29 & 8,5 & $-4,6$ & 42 & $-48,9$ & 0,421 \\
\hline 30 & 9,3 & $-5,2$ & 49 & $-49,4$ & 0,383 \\
\hline 31 & 9,8 & $-3,5$ & 56 & $-49,6$ & 0,375 \\
\hline
\end{tabular}

Tabela 7. Análise estatística para Intermodulação.

\begin{tabular}{crrrr}
\hline Termo & \multicolumn{1}{c}{ Coef } & SE Coef & \multicolumn{1}{c}{ T } & \multicolumn{1}{c}{ P } \\
\hline Constante & $-49,3966$ & 0,3991 & $-123,782$ & 0,000 \\
Corrente & $-2,8551$ & 0,3866 & $-7,385$ & 0,000 \\
Potência & 0,4776 & 0,6211 & 0,769 & 0,451 \\
Canal & 3,1657 & 0,7791 & 4,063 & 0,001 \\
Corrente*Corrente & 0,4945 & 0,8679 & 0,570 & 0,575 \\
Potência*Potência & 1,7101 & 1,3385 & 1,278 & 0,216 \\
Canal*Canal & 3,3172 & 1,2826 & 2,586 & 0,018 \\
Corrente*Potência & 1,7528 & 0,7973 & 2,198 & 0,040 \\
Corrente*Canal & $-4,5883$ & 1,4267 & $-3,216$ & 0,004 \\
Potência*Canal & $-1,5300$ & 1,9615 & $-0,780$ & 0,445 \\
\hline & & & &
\end{tabular}

Tabela 8. Análise estatística para Eficiência.

\begin{tabular}{crrrc}
\hline Termo & \multicolumn{1}{c}{ Coef } & SE Coef & \multicolumn{1}{c}{ T } & P \\
\hline Constante & 0,411077 & 0,002849 & 144,291 & 0,000 \\
Corrente & $-0,053600$ & 0,002760 & $-19,420$ & 0,000 \\
Potência & 0,012715 & 0,004434 & 2,868 & 0,010 \\
Canal & 0,007106 & 0,005562 & 1,278 & 0,216 \\
Corrente* Corrente & 0,022293 & 0,006196 & 3,598 & 0,002 \\
Potência*Potência & 0,006423 & 0,009556 & 0,672 & 0,509 \\
Canal*Canal & $-0,001667$ & 0,009157 & $-0,182$ & 0,857 \\
Corrente*Potência & $-0,000602$ & 0,005692 & $-0,106$ & 0,917 \\
Corrente ${ }^{*}$ Canal & $-0,021972$ & 0,010186 & $-2,157$ & 0,043 \\
Potência*anal & $-0,016817$ & 0,014003 & $-1,201$ & 0,244 \\
\hline
\end{tabular}

resíduos seguem uma distribuição normal, os pontos descreverão, aproximadamente, uma linha no gráfico de probabilidade. Para esses dados, o gráfico de probabilidade normal dos resíduos mostra que se pode pressupor que estes resíduos seguem uma distribuição normal. Testes de resíduos usando a estatística de Anderson-Darling também confirmam os achados gráficos.

A normalidade também pode ser avaliada através do histograma. A Figura13 mostra os gráficos de superfície e resíduos para as resposta, gerados pelo software Minitab.

É possível modelar cada uma das respostas esperadas individualmente com grau bastante elevado de precisão. Entretanto, a otimização de cada resposta raramente leva a uma solução de compromisso que atende a maioria dos objetivos.

Atentos a este tipo de problema de otimização de respostas e seguindo a idéia de agregação de múltiplos objetivos, Derringer e Suich (1980) propuseram um algoritmo para otimização simultânea de várias respostas, as quais dependem de um dado número de fatores independentes ou de um conjunto de condições. Com esta abordagem, a transformação é conduzida para cada uma das $p$ respostas resultando em uma função de utilidade (desirability) individual $d_{i}$, com $0 \leq d_{i} \leq 1$. Neste método, o modelo estatístico é primeiramente obtido usando mínimos quadrados ordinários (ordinary least square). Os valores individuais obtidos através da transformação são então combinados utilizando média geométrica, compondo o índice de desirability global $(D)$ como sendo:

$D=\left[\prod_{i=1}^{n} d_{i}^{w_{i}}\left(\hat{Y_{i}}\right)\right]^{\frac{1}{W}}$

onde $w_{i}$ é o peso individual da resposta $\hat{Y}_{i}$ e $W$ leva a média geométrica. 0 peso define a forma da função de desirability para cada resposta. Para cada resposta é possível selecionar um peso de 0,1 a 10 para diminuir ou aumentar a ênfase em cada alvo. A Figura14 ilustra este conceito.

0 valor de $D$ leva a solução de compromisso e está restrito ao intervalo $[0,1]$. $D$ é próximo de 1 quando as respostas estão perto das especificações. 0 tipo de transformação depende da direção da otimização desejada. Para a Intermodulação o alvo é a minimização da resposta, com alvo fixado em $-48 \mathrm{dBc}$, máximo de $-46 \mathrm{dBc}$ e peso de 0,1 . Para a Eficiência o alvo é a maximização da resposta, com alvo fixado em 0,4, mínimo de 0,36 e peso de 0,1 . Foi dada a mesma importância para as duas respostas. 
A solução otimizada para minimizar a Intermodulação e maximizar a Eficiência pode ser obtida usando a função desirability de Derringer e Suich, conforme mostra a Figura 15. A desirability composta prevista foi de 1 , onde o valor 1 representa um perfeito ponto de ótimo, e a solução global para o problema proposto pode ser então dada por:

- Canal $=42$

- Potência de Entrada = -4,04 dBm

- Corrente $=8,99 \mathrm{~A}$

\subsection{Experimentos confirmatórios}

Para uma indústria de telecomunicações, de nada adianta ter um amplificador customizado para um único ponto ótimo, pois é preciso suprir o mercado com amplificadores banda larga que acomodem todas as situações possíveis nas instalações de equipamentos. Assim, é necessário levar todos os canais de UHF para o ponto ótimo, garantindo um bom desempenho em toda a faixa de frequência e aumentando a confiabilidade e a produtividade dos amplificadores por uma menor dispersão dos valores de Eficiência e Intermodulação.

Utilizando esta abordagem foi realizado um experimento de confirmação para oito canais de operação e testes de hipóteses foram aplicados para avaliar os resultados. Os resultados destes testes são apresentados nas Tabelas 9 e 10. Os Valores- $P$ menores que 0,05 mostram que houve aumento da Eficiência, quando comparada com o valor médio de 41\%, e houve redução da Intermodulação, quando comparada com a média de $-48,2 \mathrm{dBc}$.

Pode-se verificar através do teste de hipóteses a diferença entre os valores estimados pelo conceito de Derringer e Suich (1980) e os valores obtidos na prática, ou seja, a diferença entre o comportamento original do amplificador sem o uso de nenhuma técnica de otimização e o resultado final obtido. Esta otimização foi realizada para os canais dentro da faixa de UHF, mas pode ser utilizada para as demais frequências do espectro de televisão.

Tabela 9. Tabela de fatores ótimos para eficiência.

\begin{tabular}{ccllcccc}
\hline \multicolumn{1}{c}{ Variável } & N & \multicolumn{1}{c}{ Média } & \multicolumn{1}{c}{ DP } & Média SE & 95\% Limite inferior & T & P \\
\hline Valores estimados & 8 & 0,41750 & 0,00707 & 0,00250 & 0,41276 & 3,00 & 0,010 \\
Valores obtidos & 8 & 0,41375 & 0,00744 & 0,00263 & 0,40877 & 1,43 & 0,099 \\
Valores originais & 8 & 0,4100 & 0,0298 & 0,0105 & 0,3901 & 0,00 & 0,500 \\
\hline
\end{tabular}

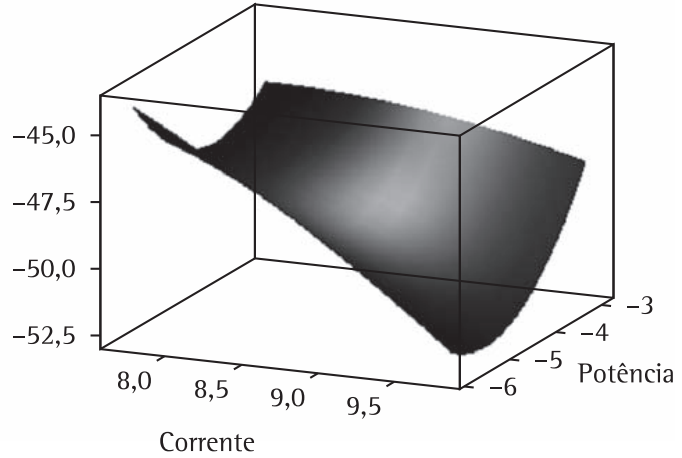

Gráfico de probabilidade normal para intermodulação

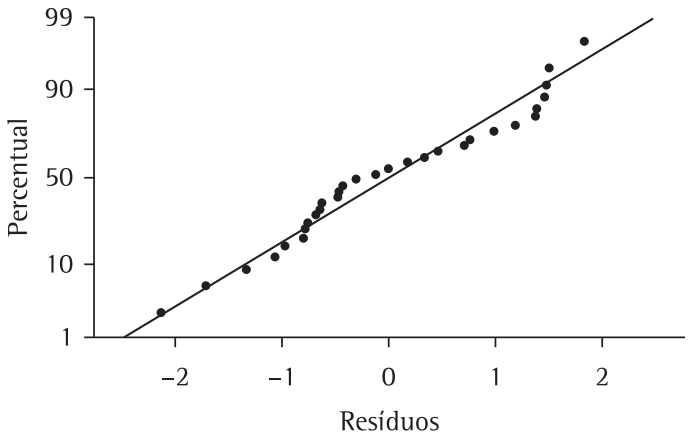

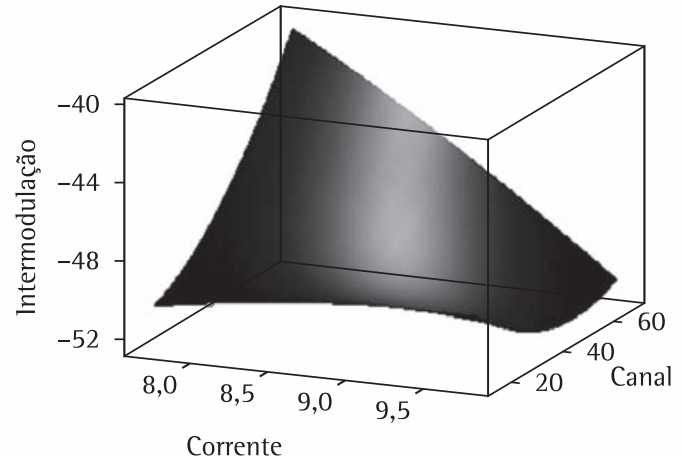

Resíduos vs. observação para eficiência

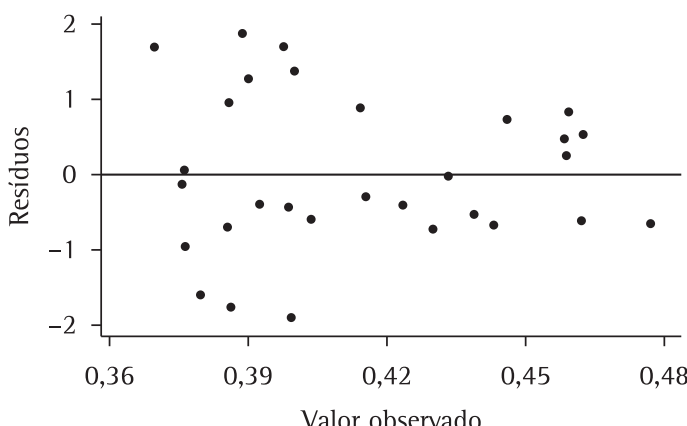

Figura 13. Gráfico de superfície e resíduos para intermodulação e eficiência. 


\begin{tabular}{|c|c|}
\hline Peso & Função de Desirability \\
\hline $\begin{array}{c}\text { Um peso menor que 1 } \\
\text { coloca menos ênfase no } \\
\text { alvo; uma resposta longe } \\
\text { do alvo pode levar a um } \\
\text { desirability alto. }\end{array}$ & $\mathrm{d}=0$ \\
\hline $\begin{array}{c}\text { Um peso igual a 1 coloca } \\
\text { ênfase idêntica no alvo e } \\
\text { nos limites. 0 desirability } \\
\text { para a resposta aumenta } \\
\text { linearmente. }\end{array}$ & \\
\hline $\begin{array}{c}\text { 1 } \\
\text { estar muito próxima do } \\
\text { alvo para ter um } \\
\text { desirability alto. }\end{array}$ & $\mathrm{d}=1$ \\
\hline 10
\end{tabular}

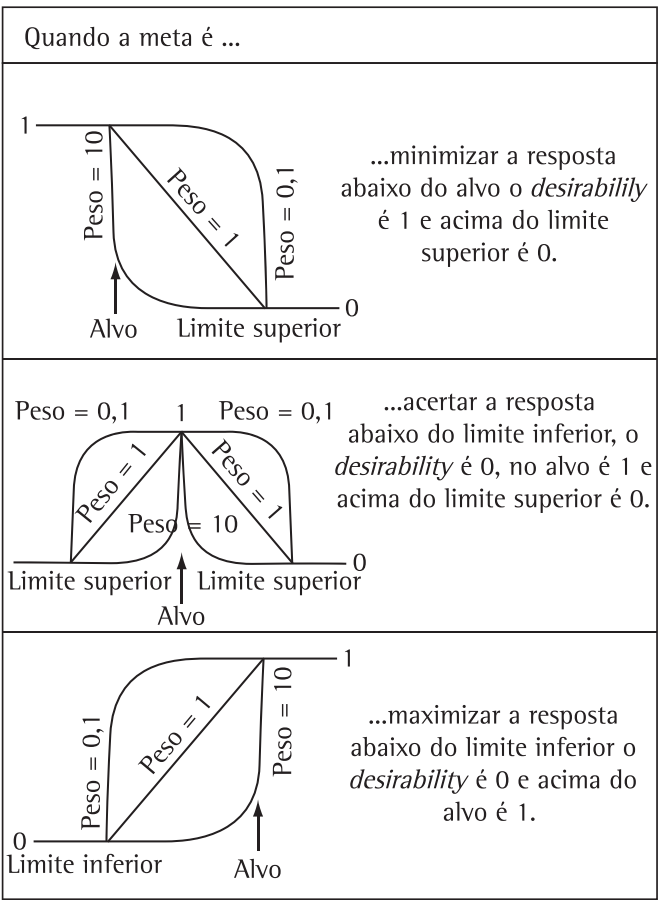

Figura 14. Desirability de Derringer.

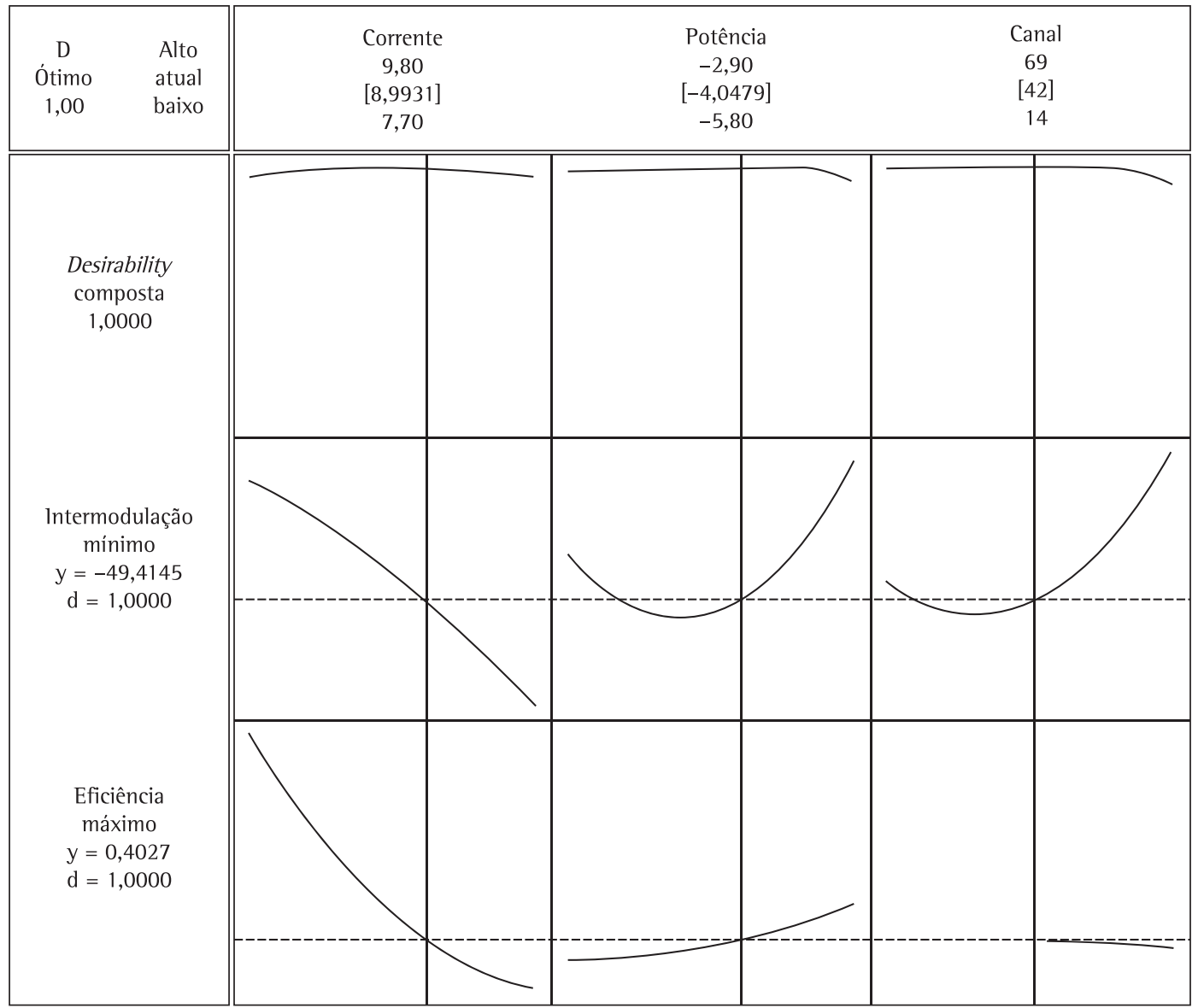

Figura 15. Desirability de Derringer e Suich. 
Tabela 10. Tabela de fatores ótimos para intermodulação.

\begin{tabular}{lccccccc}
\hline \multicolumn{1}{c}{ Variável } & $\mathrm{N}$ & Média & DP & Média SE & 95\% Limite inferior & T & P \\
\hline Valores estimados & 8 & $-52,625$ & 0,744 & 0,263 & $-52,127$ & $-16,82$ & 0,000 \\
Valores obtidos & 8 & $-53,500$ & 0,926 & 0,327 & $-52,880$ & $-16,19$ & 0,000 \\
Valores originais & 8 & $-48,238$ & 1,759 & 0,622 & $-47,059$ & $-0,06$ & 0,477 \\
\hline
\end{tabular}

\section{Conclusões}

Duas variáveis respostas - Intermodulação e Eficiência - foram analisadas e otimizadas utilizando a abordagem experimental proposta neste trabalho, permitindo realizar as seguintes afirmações com relação às questões levantadas na seção 3 .

Os fatores envolvidos no processo de amplificação que mais contribuem para o aumento de Intermodulações são o Canal de operação e a Corrente de polarização. Para esta resposta, há uma forte interação entre a Corrente e a Potência, e entre a Corrente e o Canal.

A Eficiência também é afetada pela Corrente e pela Potência, mas a melhoria obtida na otimização desta resposta foi menos significante que a obtida para a Intermodulação.

É possivel escolher valores ótimos para os fatores envolvidos no processo de amplificação de tal forma a obter Intermodulações reduzidas e melhores Eficiências. A escolha ótima destes fatores permite obter amplificadores com melhor desempenho e, por consequência, maior qualidade. 0 aumento da qualidade é percebido com a diminuição dos refugos na linha de produção por não atendimento aos requisitos técnicos, aumentando assim a produtividade.

Verificou-se ser possível utilizar um mesmo amplificador para atender toda a faixa de frequência de UHF (canais 14 a 69) com desempenho satisfatório, desde que os valores ótimos dos fatores estudados sejam escolhidos. Desta forma, para o transistor utilizado neste estudo, foi possível obter um amplificador banda larga capaz de atender um maior número de clientes com um mesmo produto.
0 experimento aqui apresentado foi realizado em amplificadores para televisão digital na faixa de UHF, mas a mesma abordagem pode ser utilizada para qualquer outro amplificador em outras faixas de frequência. A inovação deste trabalho está na utilização de DOE e análises estatísticas para avaliação e otimização de circuitos eletrônicos, ferramentas normalmente não utilizadas nesta área, mas que se mostraram adequadas também para este tipo de problema e mais eficientes do que o método tradicional de tentativa e erro.

A fim de garantir a manutenção da qualidade dos amplificadores com o passar do tempo, novas coletas e análises de dados devem ser realizadas para garantir a eficácia do processo produtivo. Além disso, pode-se realizar um estudo de viabilidade econômica para demonstrar a redução de custos que esta abordagem pode trazer pela redução do tempo de produção e pela redução do estoque.

\section{Referências}

ADVANCED TELEVISION SYSTEMS COMMITEE - ATSC. ATSC Recommended Practice: Transmission Measurement and Compliance for Digital Television. Washington, D.C., 26 de Maio de 2008. (Documento A/64B).

BARROS NETO, B.; SCARMINIO, 1. S.; BRUNS, R. E. Planejamento e Otimização de Experimentos. 2. ed. Campinas: Editora Unicamp, 1996. p. 60-131.

COLEMAN, D. E.; MONTGOMERY, D. C. A systematic approach to planning for a designed industrial experiment. Technometrics, v. 35, n. 1, p. 1-12, 1993.

DERRINGER, G.; SUICH, R. Simultaneous Optimization of Several Response Variables. Journal of Quality Technology, v. 12, n. 4, out. 1980.

JEONG, J. High Efficiency RF and Microwave Power Amplifiers with Non-constant Envelope Signals. Los Angeles: University of California, 2006.

\title{
Radio frequency broadband amplifiers performance optimization: an experimental approach
}

\begin{abstract}
This paper evaluates radio frequency (RF) power amplifiers behavior for telecommunications applications. An experimental strategy was employed resulting in the optimization of a number of factors responsible for increasing the overall efficiency and linearity of amplifiers during production process, reducing total intermodulation and interference in adjacent channels. These results enabled broadband amplifiers manufacturing with high efficiency, thus ensuring increased productivity and reliability.
\end{abstract}

Keywords

Radio frequency (RF) amplifier. Intermodulation. Reliability. DOE. 